\title{
Rectifier Fault Diagnosis and Fault Tolerance of a Doubly Fed Brushless Starter Generator
}

\author{
Liwei Shi and Zhou Bo \\ School of Traffic \& Vehicle Engineering, Shandong University of Technology, Zibo, Shandong 250049, China \\ Correspondence should be addressed to Liwei Shi; liwei10@nuaa.edu.cn
}

Received 25 August 2014; Accepted 7 October 2014

Academic Editor: Sergiu Dan Stan

Copyright ( 2015 L. Shi and Z. Bo. This is an open access article distributed under the Creative Commons Attribution License, which permits unrestricted use, distribution, and reproduction in any medium, provided the original work is properly cited.

\begin{abstract}
This paper presents a rectifier fault diagnosis method with wavelet packet analysis to improve the fault tolerant four-phase doubly fed brushless starter generator (DFBLSG) system reliability. The system components and fault tolerant principle of the high reliable DFBLSG are given. And the common fault of the rectifier is analyzed. The process of wavelet packet transforms fault detection/identification algorithm is introduced in detail. The fault tolerant performance and output voltage experiments were done to gather the energy characteristics with a voltage sensor. The signal is analyzed with 5-layer wavelet packets, and the energy eigenvalue of each frequency band is obtained. Meanwhile, the energy-eigenvalue tolerance was introduced to improve the diagnostic accuracy. With the wavelet packet fault diagnosis, the fault tolerant four-phase DFBLSG can detect the usual opencircuit fault and operate in the fault tolerant mode if there is a fault. The results indicate that the fault analysis techniques in this paper are accurate and effective.
\end{abstract}

\section{Introduction}

A starter generator can start the engine and supply electrical power for the aeronautics and automobiles. A variable frequency starter generator is developed for the Boeing 787 which is introduced in [1]. The switched reluctance machine (SRM) [2] and the PM machine [3] were also considered as starter generators. However, the controlled power electronic circuit for switched reluctance generator is very complex and expensive. And the PM material is very strict with the working temperature $[4,5]$. It is difficult for both of the SRM and PM machine to regulate the output voltage when they work as generators.

Doubly fed brushless starter generator (DFBLSG) is a new type of brushless DC machine that comes from doubly salient PM machine by using field winding instead of permanent magnet steel [6]. Its armature windings and excitation windings are both mounted on the salient poles of the stator, and it has similar salient rotor structure to SRM rotor. As a generator, DFBLSG does not need rotor position information and controlled power electronic circuit in the SRM generator. DFBLSG has such advantages as simple structure, low cost, high reliability, and good fault tolerance. Thus it has good application prospects in many fields including wind power generation, aeronautics, astronautics, automobiles, and ships [7]. In particular, it can be employed as aeronautics starter generator because it has excellent performance on both power generation and starting $[8,9]$.

The fault tolerant schematic of a machine system is shown in Figure 1. When a multiphase machine with more than three phases is implemented in the system, it can continue operating even with one or two open-circuit phases at the monitor of deferent sensors. So, it is necessary to build a system for fault tolerant application with the fault detecting sensors and controller $[10,11]$.

Generating mode is of particular importance for the starter and generator. As a weak part of the doubly fed brushless generator system, the rectifier is prone to failure. Practice shows that the faults of rectifier could be divided into short-circuit fault and open-circuit fault. Short-circuit fault would result in stopping operation by a fuse [8]. On occurrence of open-circuit fault, the unbalanced operating condition of rectification circuit would cause output voltage variation, phase current distortion, and even system crashes. Therefore, the research on rectifier faults detecting for doubly fed brushless starter generator is significantly important. 


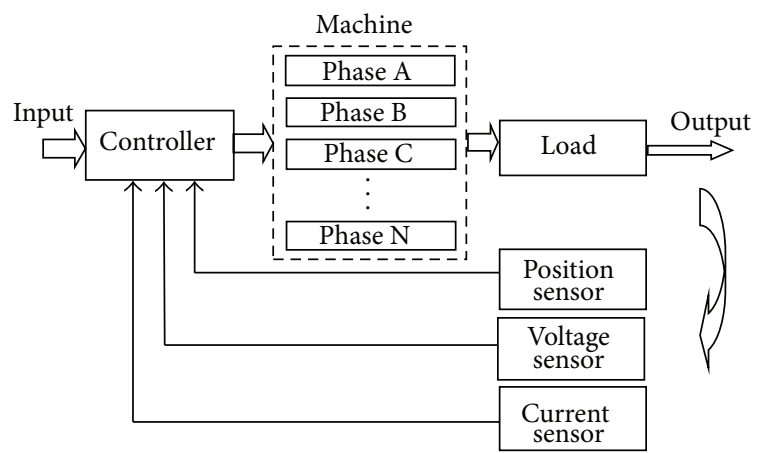

FIGURE 1: Fault tolerant schematic of a machine system.

Recently, there are many different methods raised for rectifier fault diagnosis applications. The primary idea is diagnosing fault information included in output voltage. To detect the fault of a rectifier with 12 phases, an approach is given on the basis of voltage analysis with voltage eigenvalue in [12]. An extended Kalman filter is used to estimate the unknown model parameters for nonlinear dynamic systems [13]. Fourier transform and wavelet analysis has been used in fault diagnosis in [14-16]. In [14], a novel method for gearbox fault detection based on biorthogonal B-spline wavelet was proposed. And in [15], an automatic identification method for the leakage signal of petroleum pipeline is studied. The wavelet analysis is used to process the input signal because it has the superiority of varied size of the analysis window to the frequency [16].

This paper proposed a fault tolerant four-phase DFBLSG and presents a rectifier fault diagnosis method with wavelet packet analysis. The system components and fault tolerant principle of the 12/9-pole high reliable DFBLSG are given. And the common fault of the rectifier is analyzed. The process of wavelet packet transforms fault detection/identification algorithm is introduced in detail. The output voltage signal detected by a voltage sensor is used as a wavelet packet input signal. And the experiments were done to gather the energy characteristics. The wavelet coefficients were obtained from wavelet packet analysis of fault voltage signals, and then the wavelet reconstruction of each frequency band was processed. Meanwhile, the energy-eigenvalue tolerance was introduced to improve the diagnostic accuracy. With the wavelet packet fault diagnosis, the fault tolerant four-phase DFBLSG can detect the usual open-circuit fault and operate in the fault tolerant mode if there is a fault. The results indicate that the fault analysis techniques in this paper are accurate and effective.

\section{System Components and Principle}

2.1. System Components. The DFBLSG comprises machine body and its controller, as shown in Figure 2. A four-phase full-bridge inverter is used for DFBLSG drive. Phase A and phase $\mathrm{C}$ connect in series, and they build up an independent channel. The other channel is composed of phase $B$ and phase D. The position sensors are employed to detect the rotor position and rotor speed on the starting mode. And a voltage

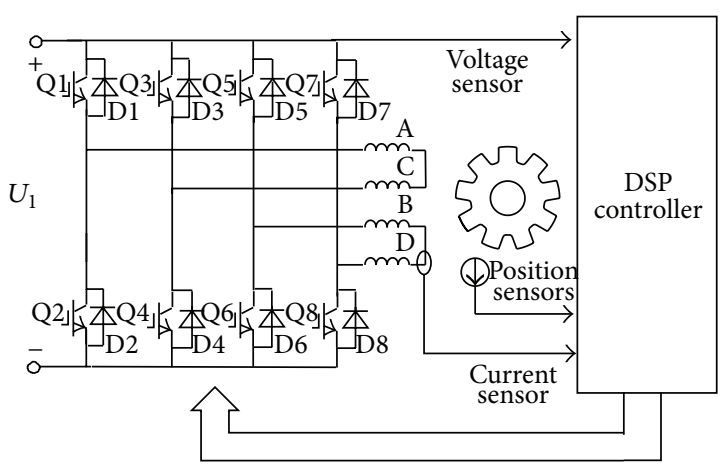

FIgURE 2: The system of the DFBLSG.

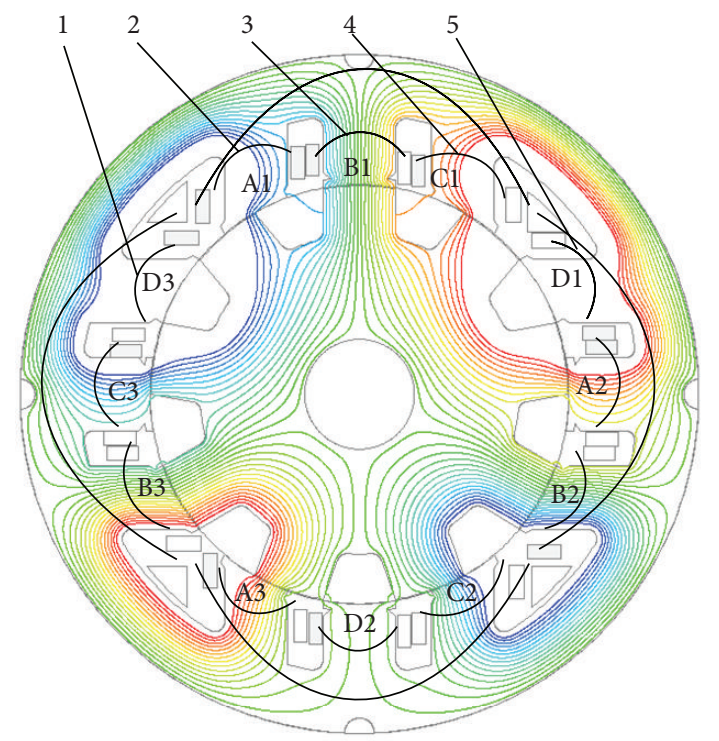

FIgURE 3: The structure and magnetic flux of the DFBLSG.

sensor is used to detect the rectifier fault. The controller is utilized to control the output voltage, the rotating of the machine, and the fault detection.

When the DFBLSG works as a generator, all the switched tubes are turned off and four-phase output voltage is rectified by the eight diodes. The output voltage is stabilized by adjusting the field winding current under the monitor of a voltage sensor.

The starter generator can output $14 \mathrm{~V} \mathrm{DC}$ source for the motor when it runs as a generator. The $12 \mathrm{~V}$ DC battery can supply DC source when the machine is required to start the engine.

2.2. Structure and Principle of DFBLSG. Figure 3 shows the structure of the novel four-phase photograph. It is different with the traditional 12/8-pole three-phase machine [17], because it has 12 stator poles and 9 rotor poles (Table 2).

Obviously, each phase winding consists of three concentrated coils. For example, phase A consists of A1, A2, and A3, which are connected in series, as shown in Figure 3. It should be noted that the phase winding direction of this configuration is different from the topology in of the traditional four-phase DFBLSG, which wounds the field coils 
TABle 1: Classification of diode open faults.

\begin{tabular}{lll}
\hline Item & Fault type & Example \\
\hline T1 & One diode or two diodes of the same loop open circuit & D1, D3, D5, D7, D2, D4, D6, D8, D1D4, D3D2, D5D8, D7D6 \\
\hline T2 & Other two diodes or more of the same channel open circuit & D1D3, D5D7, D2D4, D6D8, D1D2, D3D4, D5D6, D7D8, D1D2D3 \\
\hline T3 & Two diodes of the different channel open circuit & $\begin{array}{l}\text { D1D5, D3D7, D2D6, D4D8, D1D6, D1D8, D3D6, D3D8, D5D2, } \\
\text { D5D4, D7D2, D7D4 }\end{array}$ \\
\hline T4 & Three diodes of the different channel open circuit & D1D2D5, D1D2D6 \\
\hline
\end{tabular}

TABLE 2: Key parameters of the generator.

\begin{tabular}{lc}
\hline Item & Data \\
\hline Number of stator poles & 12 \\
Number of rotor poles & 9 \\
Stator outer diameter $(\mathrm{mm})$ & 136 \\
Rotor outer diameter $(\mathrm{mm})$ & 83.5 \\
Air gap $(\mathrm{mm})$ & 0.25 \\
Axle length $(\mathrm{mm})$ & 40 \\
Stator tooth height $(\mathrm{mm})$ & 13.8 \\
Stator yoke height $(\mathrm{mm})$ & 12 \\
Stator pole arc coefficient & 0.667 \\
Rotor pole arc coefficient & 0.5 \\
Rated power $(\mathrm{W})$ & 300 \\
Rated voltage $(\mathrm{V})$ & 14 \\
\hline
\end{tabular}

around four stator poles. But both of them have the same direction as the field coils. The phase windings of the two sections are not connected directly. Therefore, there are two channels, which are labeled as A, C and B, D.

2.3. Rectifier and Its Fault. The traditional three-phase generator has three types of rectifiers [18], which are positive fullbridge rectifier, half-wave rectifier, and negative half-wave rectifier. Similarly, the four-phase DFBLSG can also use the above rectifiers. The four-phase full-bridge rectifier shown in Figure 4, which has two independent output channels, is studied because it has the ability of fault isolation.

Rectifier is the weaknesses of the power generation system. Potential faults of the DFBLSG can be divided into short circuit and open circuit. Because the short-circuit faults are very harmful to the system, it should be protected by a fuse. Hence, this paper will mainly study diode open-circuit faults including single diode open-circuit and double diodes open-circuit faults.

On occurrence of open faults, the output voltage would be distorted in accordance with certain laws. For example, when D1 and D2 are open, the output voltage will be distorted in the first half period. So, the diode open faults can be classified into 4 types according to distortion laws of waveform, as shown in Table 1.

\section{Fault Detection Process}

In Figure 2, the voltage is detected by a voltage sensor and the analog voltage signal is sent to DSP after conditioning. Then DSP controller analyzed the sampled signal and select

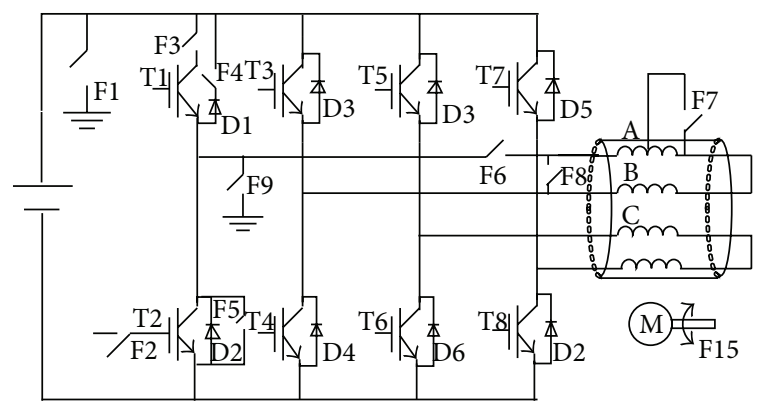

FIgURE 4: Potential faults of the DFBLSG.

fault energy eigenvalue with a wavelet packet firstly. Then, the eigenvalue is compared with a sample stored in DSP controller. If the fault condition is reached, the DSP will make appropriate decisions and output fault indication signal through the I/O port.

The fault detection process includes the following steps.

(1) Analyze the normalized voltage sampling signal with the wavelet packet, let the decomposed layer be $j$, and extract wavelet coefficient of every band [19].

The normalized equation of array $\left[P_{i}\right]$ can be described as

$$
P_{i}^{\prime}=\frac{P_{i}-P_{\min }}{P_{\max }-P_{\min }} .
$$

(2) Reconstruct the decomposition coefficients of the wavelet packet and extract the signal from every band.

(3) Calculate each band signal energy eigenvalues according to

$$
E_{2^{j}}^{k}=\sum_{i=1}^{N}\left|e_{k}(i)\right|^{2}, \quad k=0,1, \ldots, 2^{j-1},
$$

where $e_{k}(i)$ is the discrete points amplitude of the reconstructed signal.

(4) Build the fault characteristic vector $T$ that has $2^{j}$ elements with the signal energy of each frequency band:

$$
T=\left[E_{2^{j}}^{0}, E_{2^{j}}^{1}, \ldots, E_{2^{j}}^{2^{j}-1}\right] .
$$

To eliminate the influence of voltage amplitude, a new characteristic vector should be built with the element of

$s_{k}=\frac{E_{2^{j}}^{k}}{E}=\frac{\sum_{i=1}^{N}\left|e_{k}(i)\right|^{2}}{\sum_{i=1}^{2^{j-1}} E_{2^{j}}^{k}}, \quad k=0,1, \ldots, 2^{j-1}$. 


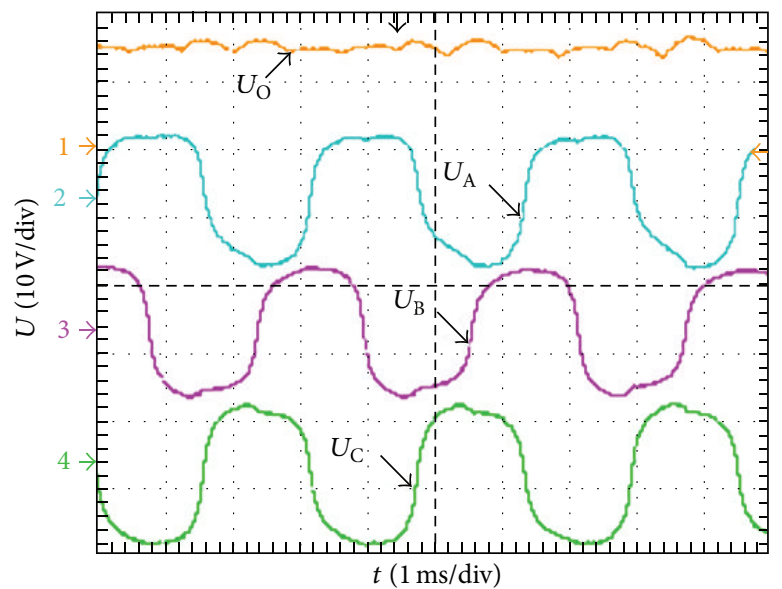

(a) Normal

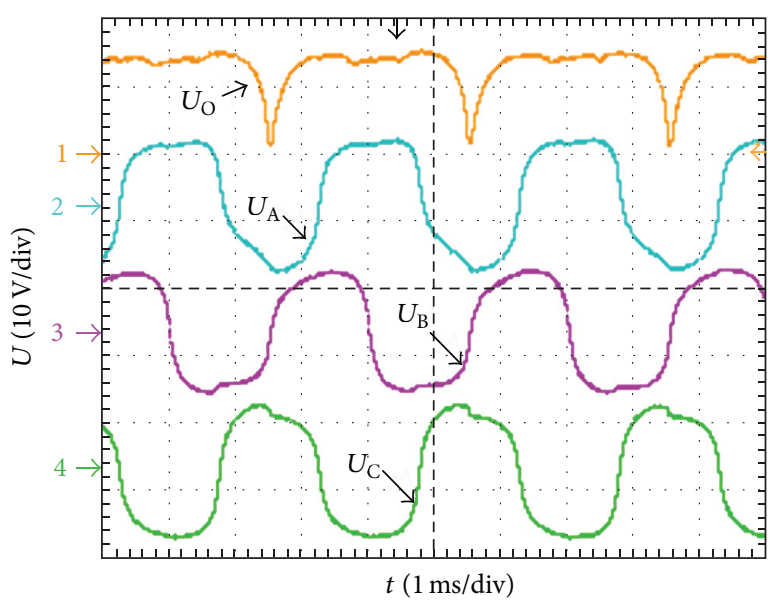

(c) T1 fault, D2 open circuit

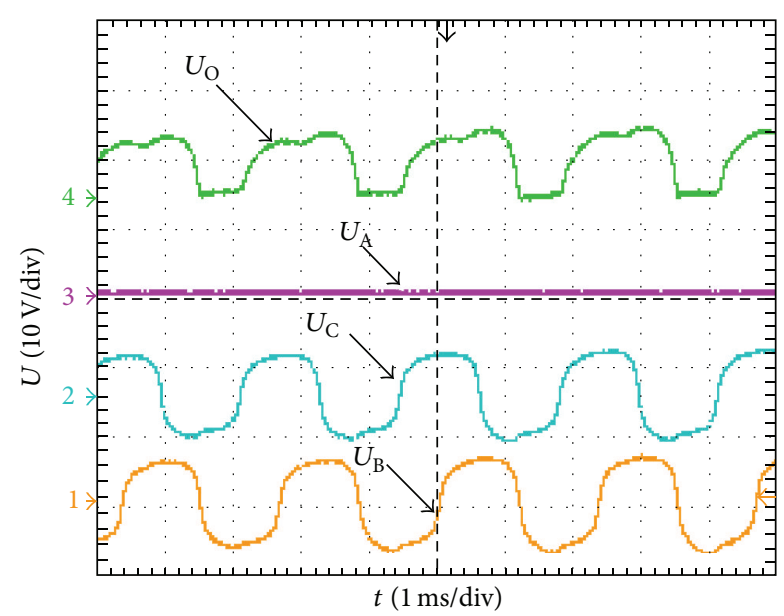

(e) T3 fault, D1D5 open circuit

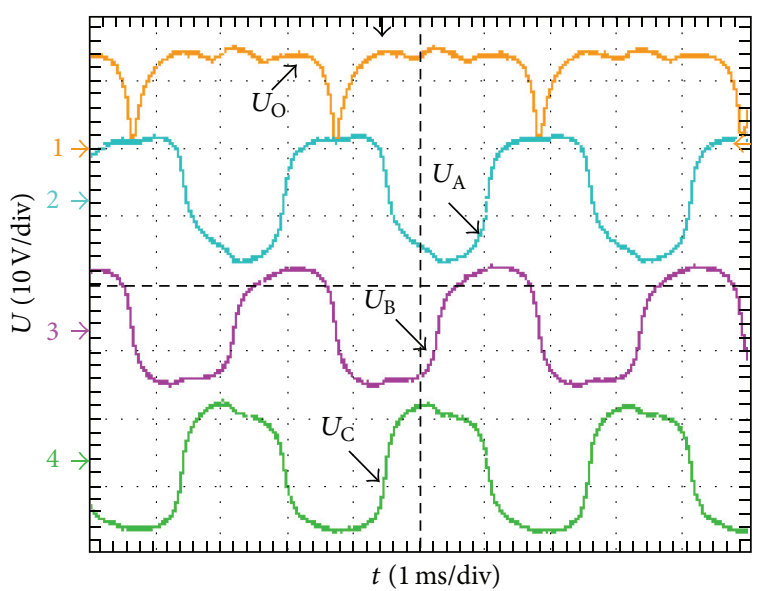

(b) T1 fault, D1 open circuit

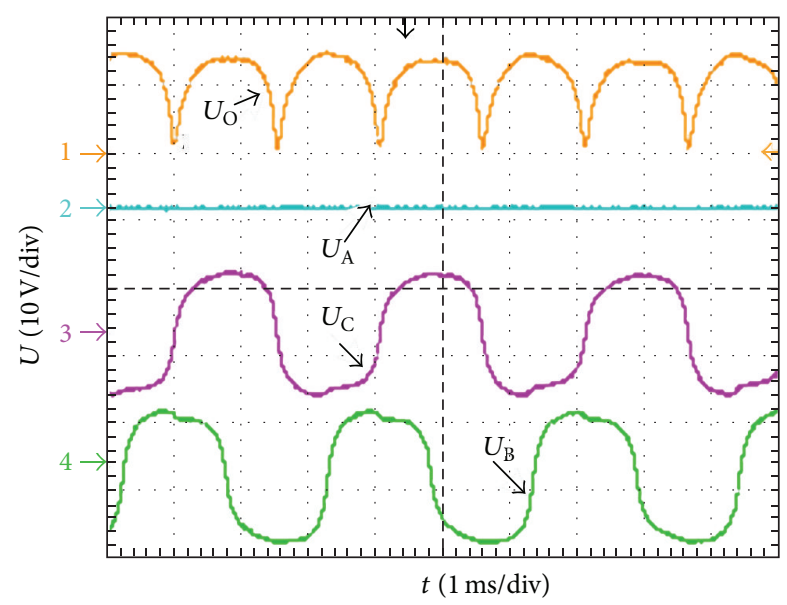

(d) T2 fault, D1D2 open circuit

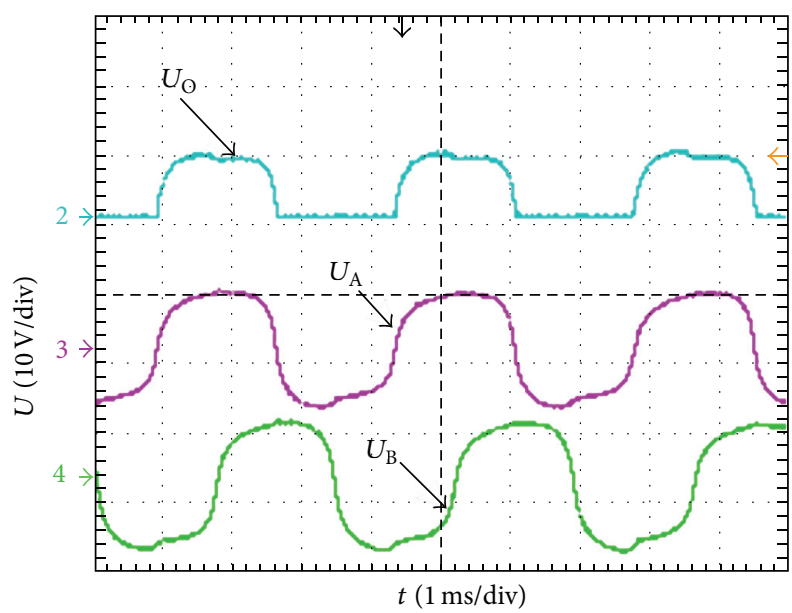

(f) T4 fault, D1D2D5 open circuit

FIGURE 5: Voltage waveforms under normal and one phase open-circuit fault. 


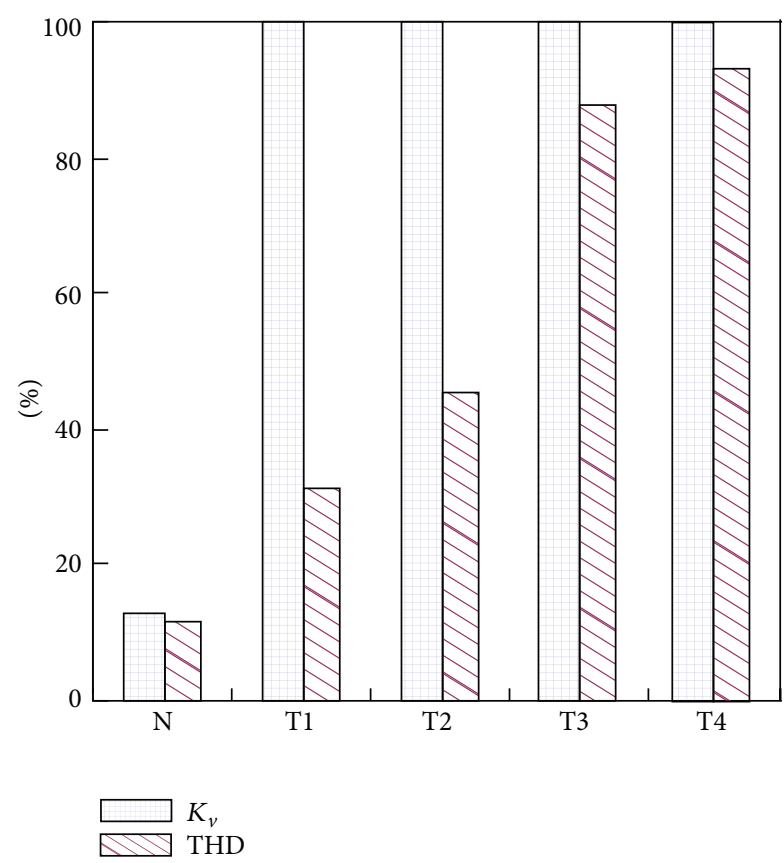

FIGURE 6: Voltage pulsating ratio and THD under normal and opencircuit fault. N: normal; T1 fault, D1 open circuit; T2 fault, D1D2 open circuit; T3 fault, D1D5 open circuit; T4 fault, D1D2D5 open circuit.

And the new characteristic vector is shown as

$$
T=\left[s_{0}, s_{1}, \ldots, s_{2^{j}-1}\right]
$$

(5) Establish the sample fault file. We should collect a large number of experimental data samples, and then the fault characteristic vector can be determined with the statistical average value of the sample.

The statistical average value can be calculated with

$$
C_{k}=\sum_{l=1}^{N} \frac{s_{k}(l)}{n}, \quad k=0,1, \ldots, 2^{j-1},
$$

where $n$ is the number of experimental times.

The error discriminant vector $\Delta P$ is used to describe the tolerance range of statistical average value $C_{k}$, and the element of $\Delta P$ can be caculated by:

$$
\Delta C_{k}=K \sigma=K \sqrt{\frac{1}{N} \sum_{l=1}^{N}\left[s_{k}(l)-C_{k}\right]^{2}},
$$

where $\sigma$ is the sample standard deviation and $K$ is the tolerance factor, generally taken to be 1 .

Equation (6) establishes mappings between energy feature vector and fault state. With the obtained fault mode parameter, a table that describes the relationship between fault state and change parameter is stored in DSP. Then the faults can be identified and displayed.

\section{Experiments and Wavelet Packet Analysis Conclusions}

4.1. Prototype Experiments. A four-phase full-bridge rectifier was built in the experimental bench. The prototype machine operating in normal state and fault state was tested. Figure 5(a) shows the voltage waveform when the machine has no fault. Figures 5(b) and 5(c) display the voltage waveform with one diode open circuit. The other two diodes or more of the same channel open-circuit fault, two diodes of the different channel open-circuit fault, and three diodes of the different channel open-circuit fault were shown in Figures 5(d)-5(f), respectively.

The equation for calculation the voltage ripple is shown in

$$
K_{v}=\frac{U_{\max }-U_{\min }}{U_{o}} .
$$

And the total harmonic distortion (THD) of voltage is expressed as

$$
\mathrm{THD}=\frac{\sqrt{\sum_{2}^{\infty} V_{i}^{2}}}{V_{1}} \times 100 \% .
$$

With the fast Fourier transform analysis of the voltage waveform obtained from the oscilloscope, the normal and various fault voltage ripple ratio and THD can be drawn in Figure 6. As can be seen from the figure, the four-phase full-bridge rectifier can tolerate the fault list in Table 1. But the voltage ripple and THD are very high when there is an open-circuit fault. So the in time detection of fault type is very necessary for us to relieve the negative influence of this voltage ripple.

Figure 7 presents the photograph of the generator and the controller. Figure 8(a) shows the nonload characteristic with a four-phase full bridge. And the external characteristic under different fault is shown in Figure 8(b) when the excitation current is $4 \mathrm{~A}$. From the figure, we can see that the generator can tolerate one-diode open-circuit faults well, because the other diode in the same leg can rectify the positive or negative current. Comparing the characteristics curves under various faults, the output voltage of single phase open circuit fault is lower than one diode open-circuit fault. The characteristic experiments results show the same conclusion with the voltage waveforms in Figure 5. Because the number of phase windings is relatively small, the external characteristic of the machine is "hard" compared to common generators. When there is a failure, the DFBLSG can achieve fault tolerance by increasing the field current or outputting a relatively low power with the same field current.

4.2. Wavelet Packet Analysis. The rectified voltage sampling frequency is $50 \mathrm{kHz}$, the sample length of oscilloscope is 2500, and the sampling repeated 10 times. According to the above diagnostic methods, we use dbl wavelet as the bases wave to carry out the wavelet packet analysis. The wavelet packet decomposition tree is shown in Figure 9 and the decomposition layer $j=5$. As an example, Figure 10 presents 


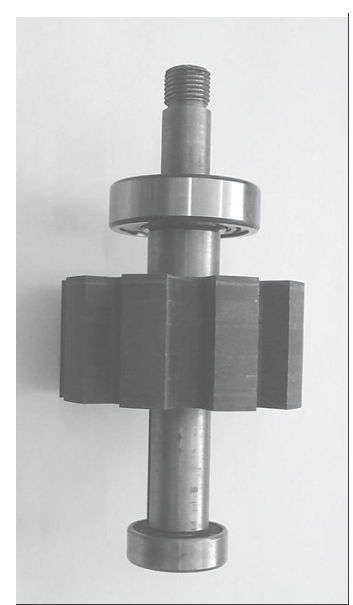

(a) Rotor

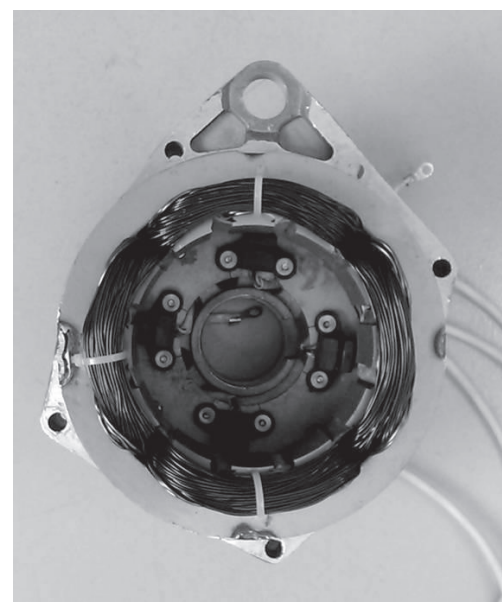

(b) Stator

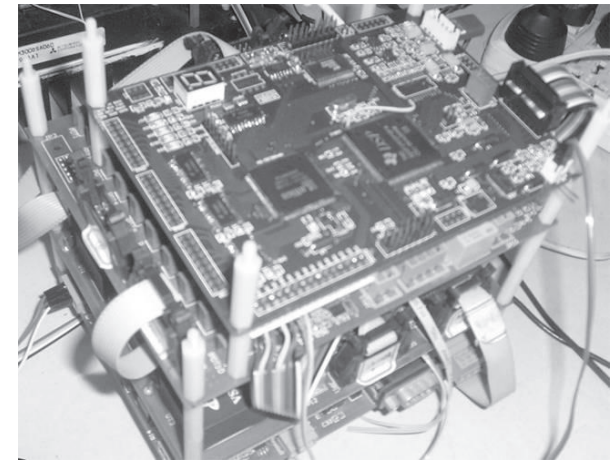

(c) DSP controller

FIGURE 7: Rotor, stator, and controller photograph.

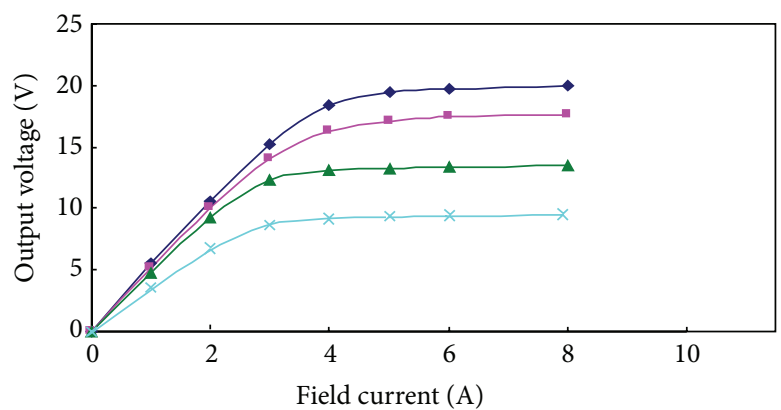

$\begin{array}{ll}\rightarrow \text { Normal circuit } & \rightarrow \text { D1D2 open circuit } \\ \rightarrow \text { D1 open circuit } & \rightarrow \text { D1D5 open circuit }\end{array}$

(a) Nonload characteristic

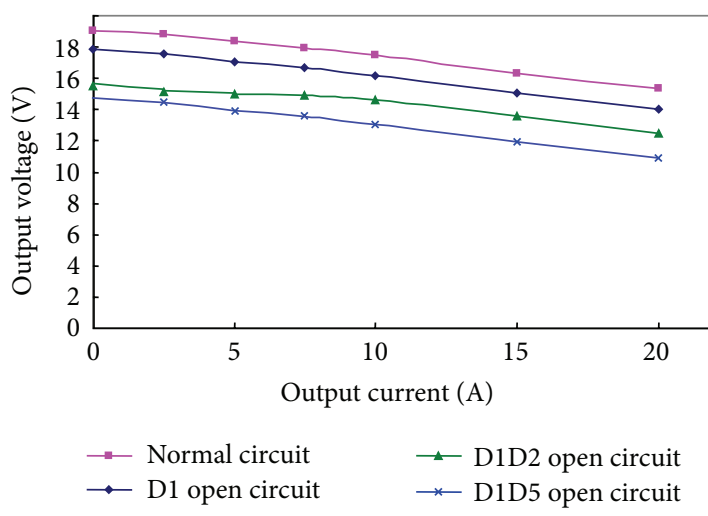

(b) External characteristic

FIgURE 8: Characteristic experiments results with full bridge mode.

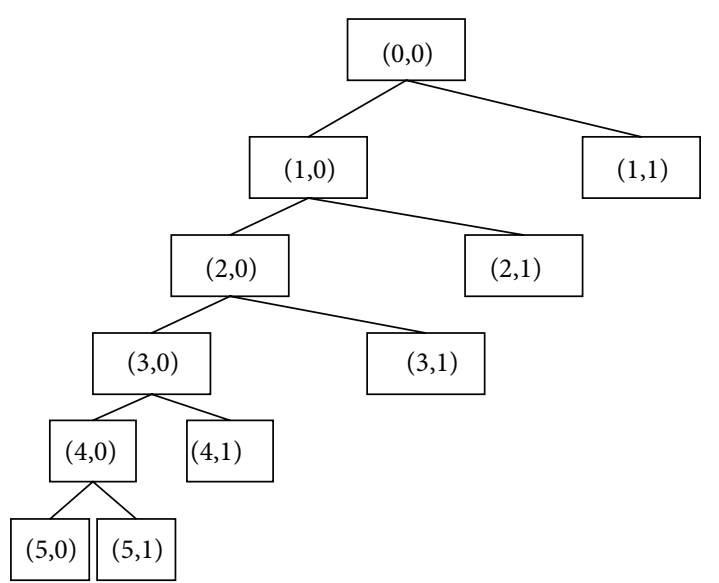

FIGURE 9: The five-layer wavelet packet decomposition tree.

the wavelet packet decomposition results of deferent band. Because the waveform describes a relative energy size, it has no unit.
TABLE 3: Energy-eigenvalue tolerance statistic on each fault condition.

\begin{tabular}{lccccc}
\hline & $\Delta C_{1}$ & $\Delta C_{2}$ & $\Delta C_{3}$ & $\Delta C_{4}$ & $\Delta C_{5}$ \\
\hline Normal & 0.008 & 0.0027 & 0.0027 & 0 & 0.0027 \\
D1 & 0.075 & 0.0023 & 0.008 & 0.004 & 0.004 \\
D1D1 open circuit & 0.11 & 0.041 & 0.010 & 0.0032 & 0.0032 \\
D1D5 open circuit & 0.04 & 0.001 & 0.0003 & 0.0003 & 0.0003 \\
D1D2D5 open circuit & 0.16 & 0.05 & 0.0012 & 0.0006 & 0.0006 \\
\hline
\end{tabular}

The energy eigenvalue statistic on each fault condition is shown in Figure 11. From the figure, we can see that the element vector data after 6th harmonic is almost zero. So these frequency band energy eigenvalues have no practical significance, and they can be negligible.

With (7), we can get the energy-eigenvalue tolerance statistic on each fault condition (Table 3).

If the system is normal, the energy characteristics of all the frequency bands are very little. If D1 is open circuit, characteristic of the first frequency band is high. If D1 and 


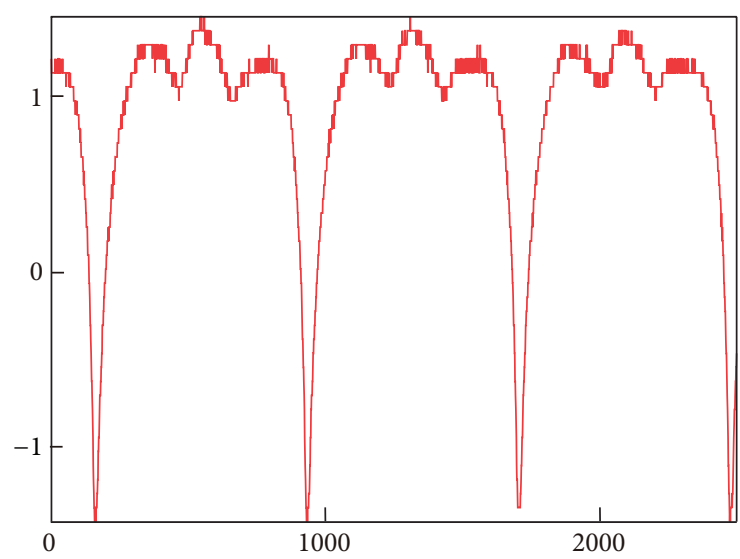

(a) Analyzed signal in case of D1 open circuit

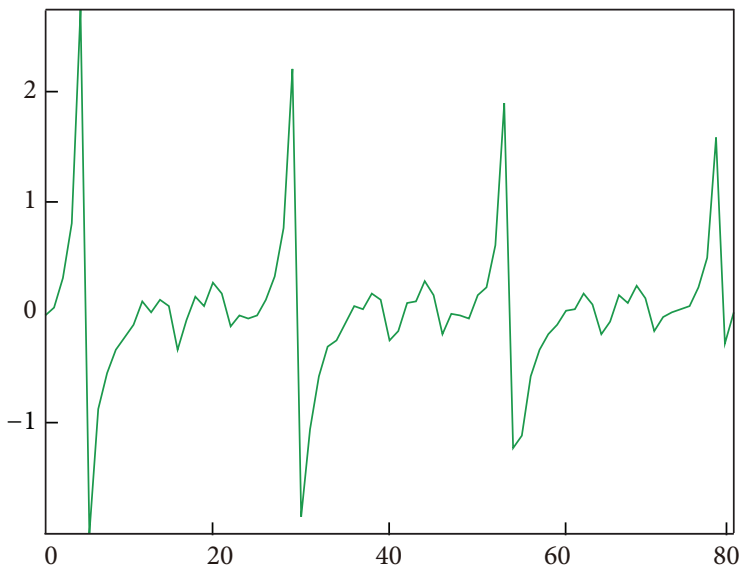

(c) Packet $(5,1)$

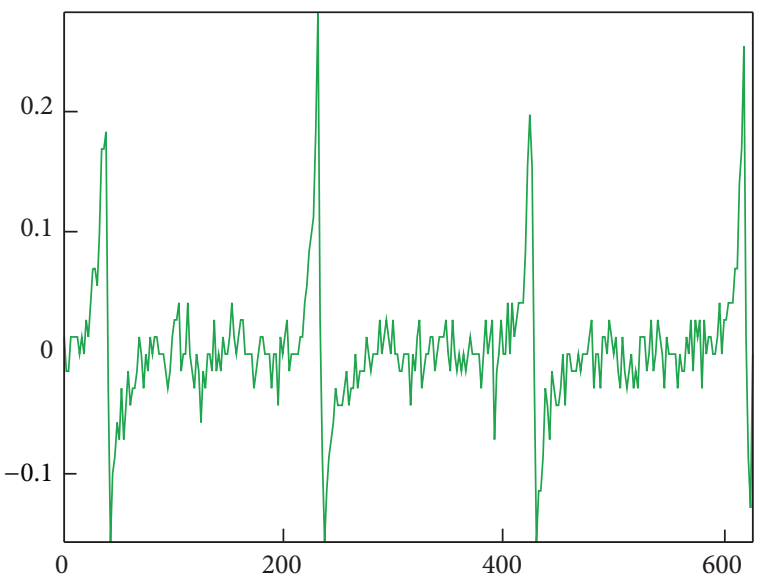

(e) Packet $(2,1)$

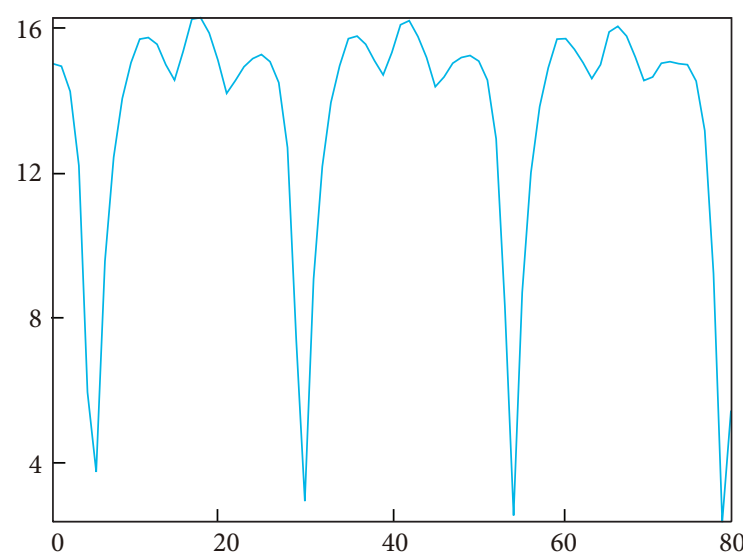

(b) Packet $(5,0)$

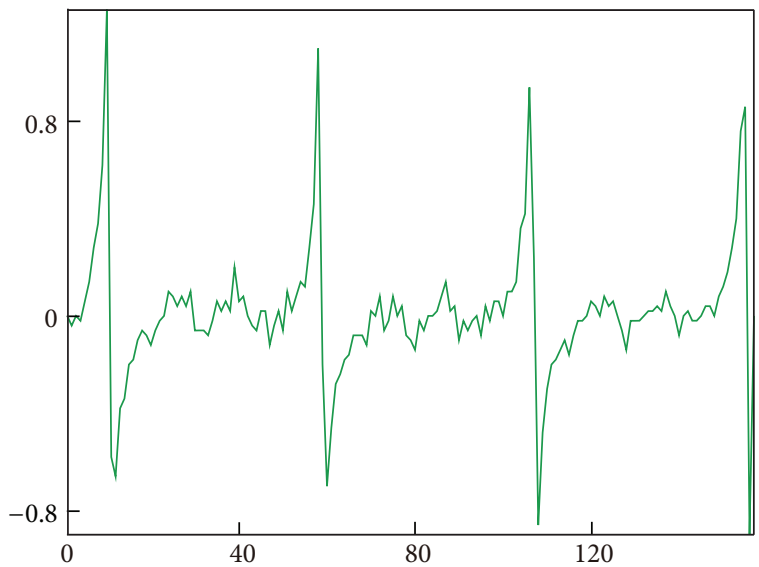

(d) Packet $(4,1)$

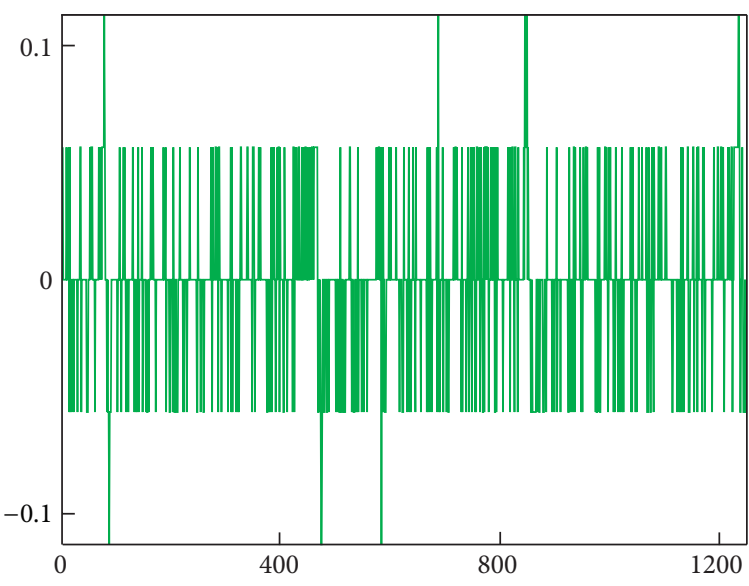

(f) Packet (1,1)

FIgURE 10: The wavelet packet decomposition results.

D2 are open circuit, the energy characteristic of the second frequency band is higher than the one of the first band. If there is an open-circuit fault on D1D5, the first and the second frequency band are almost the same. All the energy characteristics are very high if there is a D1D2D5 open-circuit fault.
The experiments prove that when the generator rectifier circuit fails, the wavelet packet analysis results of voltage on the sampling signal can be used for the fault diagnosis. With the established relationship between energy characteristics and fault state, the open-circuit fault can be recognized by the wavelet packet analysis. 


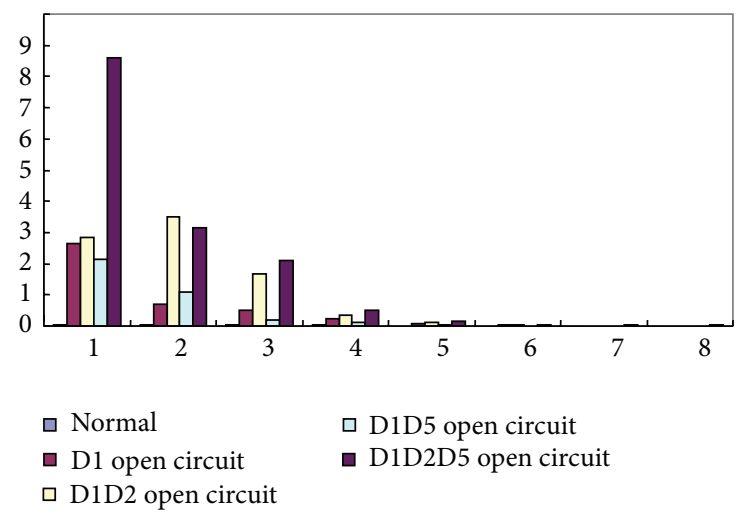

FIGURE 11: Energy eigenvalue statistic on each fault condition.

\section{Conclusions}

The doubly fed brushless starter generator has broad application prospects in the aerospace and automotive industry, which need high reliability for the whole system. To meet the requirement of the fault tolerant capability, a four-phase DFBLSG which has the characteristic of phase redundancy, phase isolation, and fault diagnosis is presented in this paper. As the weak part of the system, the rectifier faults are divided into one diode or two diodes of the same loop open circuit, two diodes of the same channel open-circuit, two diodes of the different channel open circuit, and three diodes of the different channel open circuit.

To detect the open-circuit fault of the rectifier, a rectifier fault diagnosis method with wavelet packet analysis is presented. Wavelet packet analysis can decompose the voltage signal into several layers in the whole frequency range. With the energy eigenvalues extracted from full-band wavelet packet, eigenvectors can be established to describe different faults. The fault tolerant performance and output voltage experiments were done to gather the energy characteristics with a voltage sensor. With the established relationship between energy characteristics and fault state, the opencircuit fault can be diagnosed by the wavelet packet analysis.

\section{Conflict of Interests}

The authors declare that there is no conflict of interests regarding the publication of this paper.

\section{Acknowledgments}

This paper is financially supported by the Natural Science Foundation of Shandong (no. ZR2012EM011). The authors would like to thank APSC in Nanjing University of Aeronautics and Astronautics.

\section{References}

[1] Z. Chen, H. Wang, and Y. Yan, "A doubly salient starter/generator with two-section twisted-rotor structure for potential future aerospace application," IEEE Transactions on Industrial Electronics, vol. 59, no. 9, pp. 3588-3595, 2012.
[2] W. Ding and D. Liang, "A fast analytical model for an integrated switched reluctance starter/generator," IEEE Transactions on Energy Conversion, vol. 25, no. 4, pp. 948-956, 2010.

[3] H. Mirahki, M. Moallem, and S. A. Rahimi, "Design optimization of IPMSM for $42 \mathrm{v}$ integrated starter alternator using lumped parameter model and genetic algorithms," IEEE Transactions on Magnetics, vol. 50, no. 3, pp. 114-119, 2014.

[4] C. Liu, K. T. Chau, and X. Zhang, "An efficient windphotovoltaic hybrid generation system using doubly excited permanent-magnet brushless machine," IEEE Transactions on Industrial Electronics, vol. 57, no. 3, pp. 831-839, 2010.

[5] D. Lee, Y.-H. Jeong, and S.-Y. Jung, "Design of wound rotor synchronous machine for ISG and performance comparison with interior permanent magnet synchronous machine," Transactions of the Korean Institute of Electrical Engineers, vol. 62, no. 1, pp. 37-42, 2013.

[6] Y. Du, K. T. Chau, M. Cheng, Y. Fan, W. Zhao, and F. Li, "A linear stator permanent magnet vernier HTS machine for wave energy conversion," IEEE Transactions on Applied Superconductivity, vol. 22, no. 3, Article ID 5202505, 2012.

[7] Z. Zhang, Y. Yan, and Y. Tao, "A new topology of low speed doubly salient brushless DC generator for wind power generation," IEEE Transactions on Magnetics, vol. 48, no. 3, pp. 1227-1233, 2012.

[8] L. Sun, Z. Zhang, and L. Qian, "Calculation and analysis of iron loss in Doubly Salient Brushless DC generator," in Proceedings of the 39th Annual Conference of the IEEE Industrial Electronics Society, pp. 2650-2655, November 2013.

[9] L. Zhang, B. Zhou, Y.-S. Zhang, F.-S. Cheng, and J.-D. Wei, "Analysis and suppression of torque ripple for doubly salient electro-magnetic motor," Proceedings of the Chinese Society of Electrical Engineering, vol. 30, no. 3, pp. 83-89, 2010.

[10] W. Cao, B. C. Mecrow, G. J. Atkinson, J. W. Bennett, and D. J. Atkinson, "Overview of electric motor technologies used for more electric aircraft (MEA)," IEEE Transactions on Industrial Electronics, vol. 59, no. 9, pp. 3523-3531, 2012.

[11] W. Xu, J. Zhu, Y. Zhang, and J. Hu, "Cogging torque reduction for radially laminated flux-switching permanent magnet machine with 12/14 poles," in Proceedings of the 37th Annual Conference of the IEEE Industrial Electronics Society (IECON '11), pp. 3590-3595, Melbourne, Australia, November 2011.

[12] C.-F. Zhang, M. Yan, J. He, C. Luo, and Y.-Y. Xiao, "Current sensor fault diagnosis for doubly-fed wind generator control system," Information Technology Journal, vol. 12, no. 18, pp. 4368-4373, 2013.

[13] S. Mariani and A. Ghisi, "Unscented Kalman filtering for nonlinear structural dynamics," Nonlinear Dynamics, vol. 49, no. 1-2, pp. 131-150, 2007.

[14] G. Zhang and Y. Ge, "A novel method for gearbox fault detection based on biorthogonal B-spline wavelet," Sensors and Transducers, vol. 133, no. 10, pp. 83-94, 2011.

[15] B. Zhou, J. Wang, S. Li, and W. Wang, "A new key predistribution scheme for multiphase sensor networks using a new deployment model," Journal of Sensors, vol. 2014, Article ID 573913, 10 pages, 2014.

[16] M. Aktaş, "A novel method for inverter faults detection and diagnosis in PMSM drives of HEVs based on discrete wavelet transform," Advances in Electrical and Computer Engineering, vol. 12, no. 4, pp. 33-38, 2012.

[17] F. Yang and Z. Chen, "Research on torque ripple of doubly salient electro-magnetic generator under no-load condition," 
Transactions of China Electrotechnical Society, vol. 28, no. 1, pp. 290-295, 2013.

[18] B. A. Welchko, T. A. Lipo, T. M. Jahns, and S. E. Schulz, "Fault tolerant three-phase AC motor drive topologies: a comparison of features, cost, and limitations," IEEE Transactions on Power Electronics, vol. 19, no. 4, pp. 1108-1116, 2004.

[19] X. Chen, G. Lin, and Y. Zhang, "Denoising method based on sparse representation for WFT signal," Journal of Sensors, vol. 2014, Article ID 145870, 10 pages, 2014. 

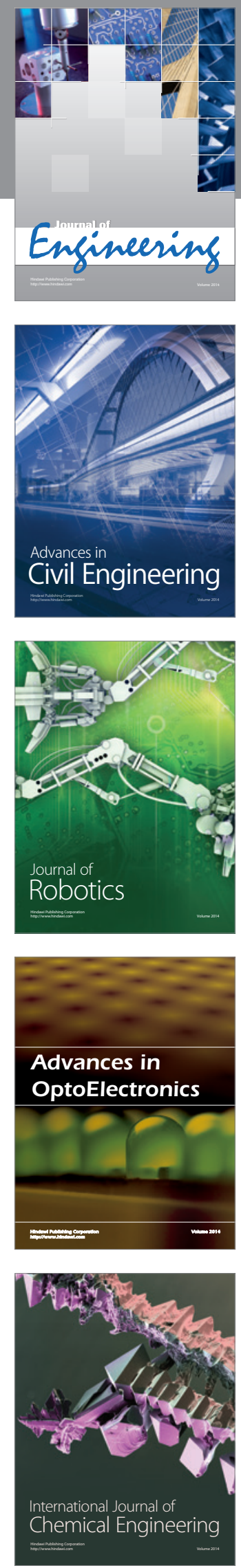

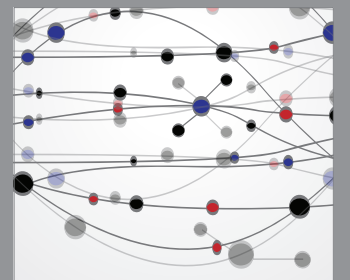

The Scientific World Journal
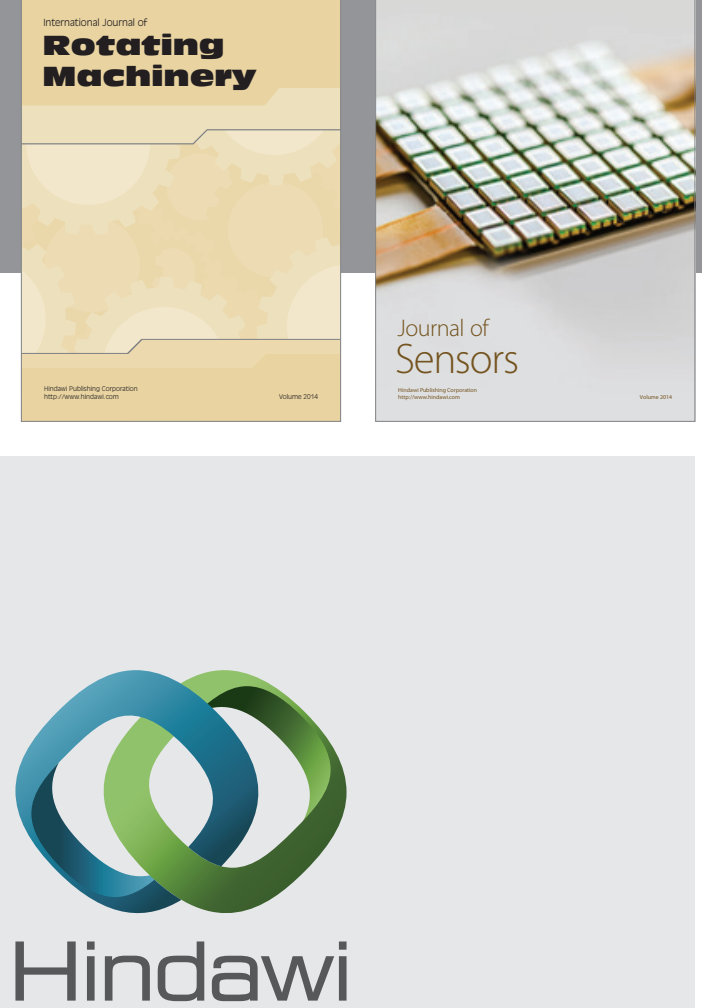

Submit your manuscripts at http://www.hindawi.com
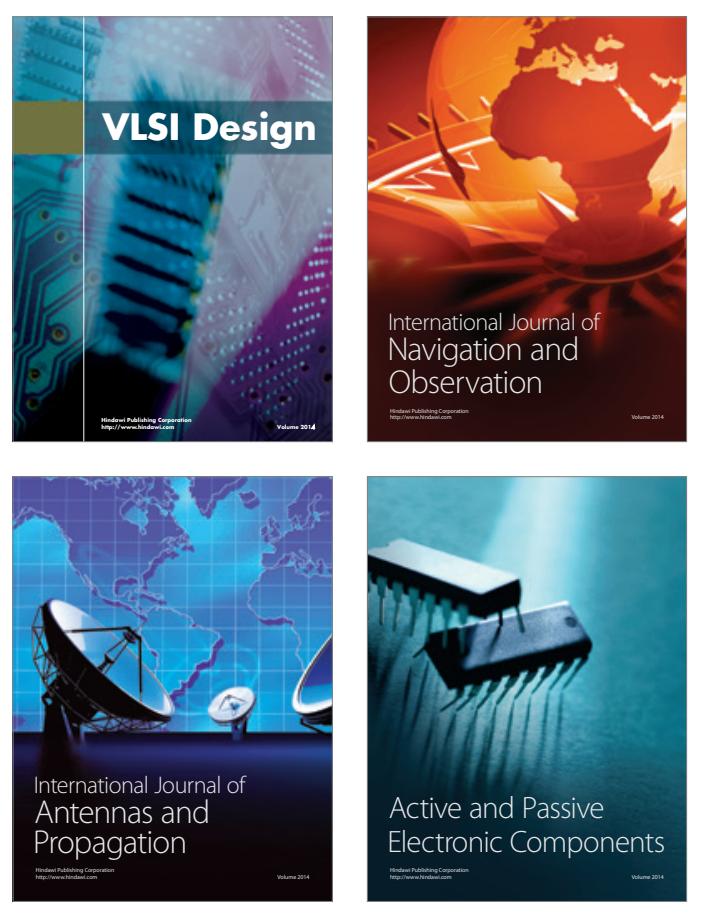
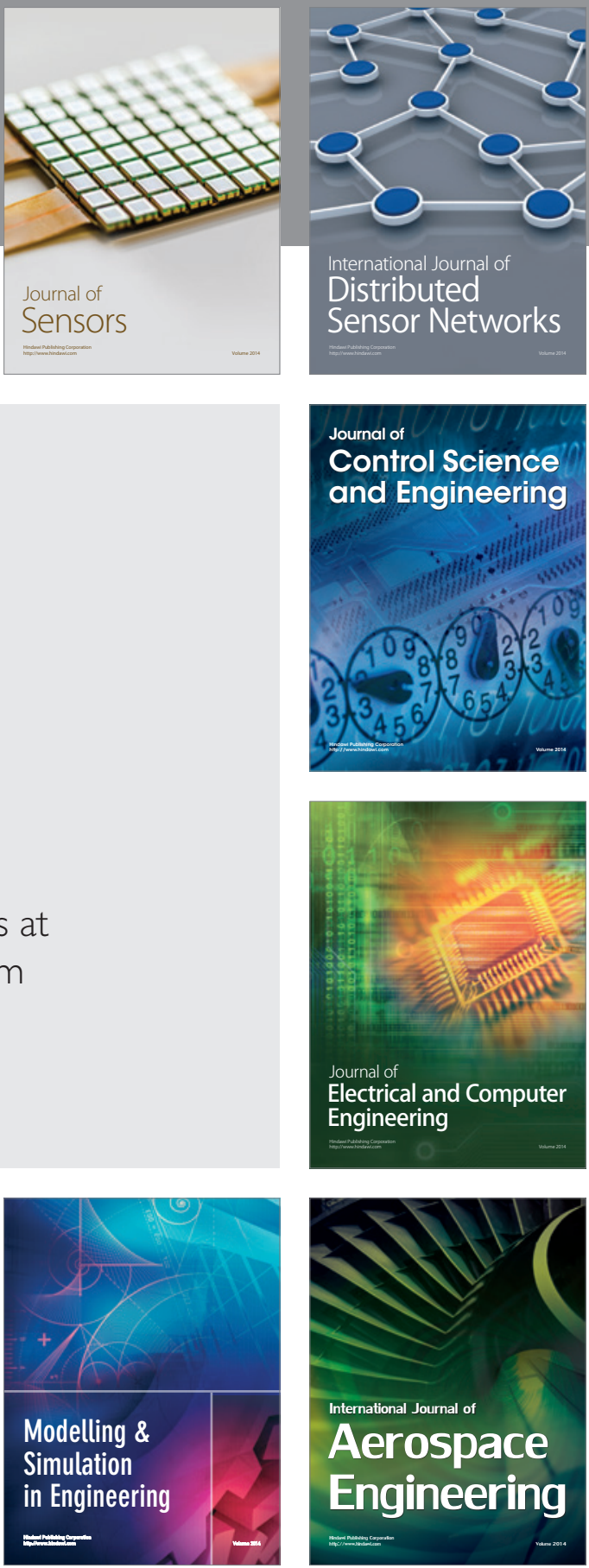

Journal of

Control Science

and Engineering
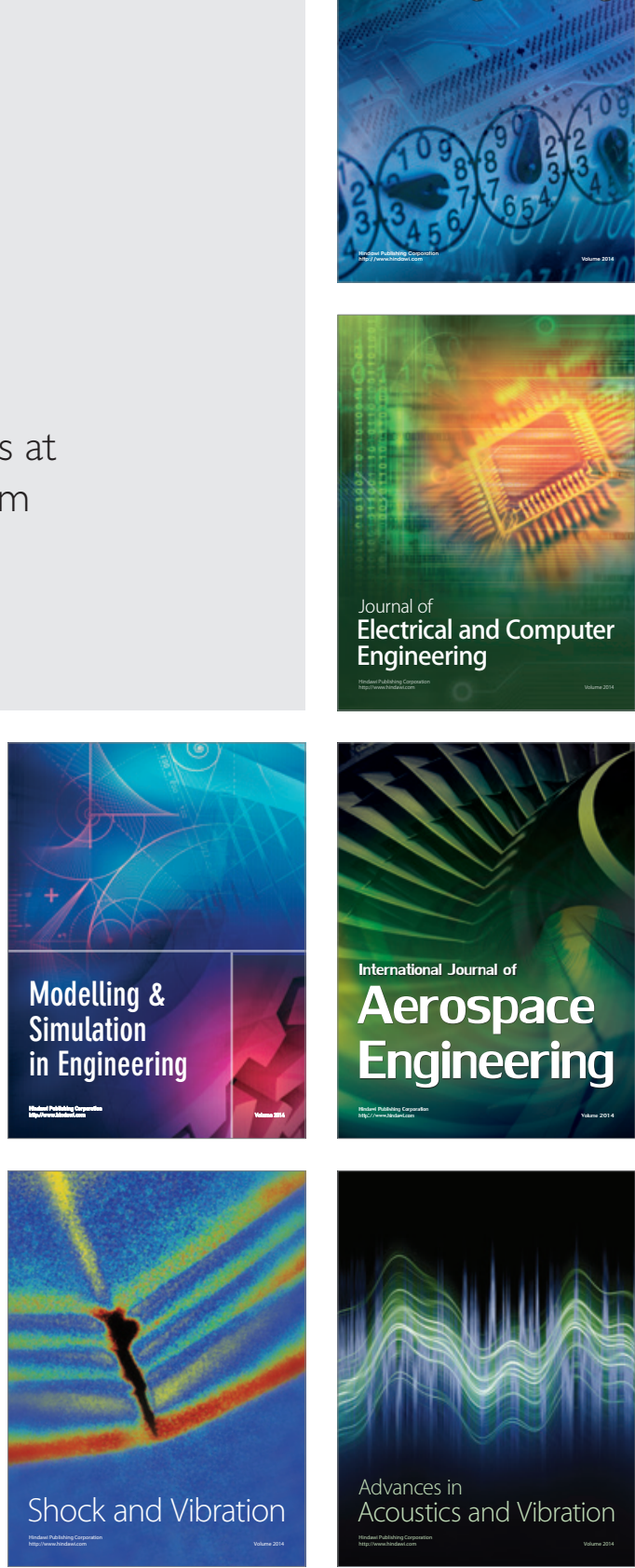